\title{
Tyrosine Phosphorylation of the 2B Subunit of the NMDA Receptor Is Necessary for Taste Memory Formation
}

\author{
Liza Barki-Harrington, Alina Elkobi, Tali Tzabary, and Kobi Rosenblum \\ Department of Neurobiology and Ethology, Faculty of Sciences, University of Haifa, Haifa 31905, Israel
}

We aimed to test whether tyrosine phosphorylation of the NMDA receptor (NMDAR) in the insular cortex is necessary for novel taste learning. We found that in rats, novel taste learning leads to elevated phosphorylation of tyrosine 1472 of the NR2B subunit of the NMDAR and increases the interaction of phosphorylated NR2B with the major postsynaptic scaffold protein PSD-95. Injection of the tyrosine kinase inhibitor genistein directly into the insular cortex of rats before novel taste exposure prevented the increase in NR2B tyrosine phosphorylation and behaviorally attenuated taste-memory formation. Functionally, tyrosine phosphorylation of NR2B after learning was found to determine the synaptic distribution of the NMDAR, since microinjection of genistein to the insular cortex altered the distribution pattern of NMDAR caused by novel taste learning.

\section{Introduction}

The postsynaptic NMDA receptor (NMDAR) is a major regulator of synaptic plasticity. NMDARs are ligand-gated ion channels that when activated, cause neuronal depolarization by generating fast EPSPs. Opening of the channel causes a transient increase in intracellular calcium, which initiates intracellular signaling. The channel is composed of NR1, which is fundamental for channel function, and NR2A-D subunits, which modulate channel gating as well as pharmacological and functional properties of the channel (Monyer et al., 1994; Cull-Candy et al., 2001).

One of the key mechanisms for regulating NMDAR function involves tyrosine phosphorylation of its NR2 subunits by the cytosolic tyrosine kinases Src and Fyn (Wang and Salter, 1994; Wang et al., 1996; Smart, 1997). Although both NR2A and NR2B undergo tyrosine phosphorylation, the Fyn kinase target tyrosine 1472 NR2B was identified as the major substrate at the postsynaptic density (Moon et al., 1994; Nakazawa et al., 2001). In vitro studies confirmed that Y1472 phosphorylation is significantly increased under various conditions, including nerve injury (Abe et al., 2005) and ethanol administration (Yagi, 1999).

Whereas NMDARs in mature neurons were initially thought to display stable expression on the plasma membrane (Lüscher et al., 1999; Ehlers, 2000), recent findings suggest that this process is dynamic. Several findings suggest that Y1472 NR2B phosphorylation plays a significant role in the trafficking of NMDARs: (1) NMDA trafficking after long-term potentiation (LTP) induction in the hippocampus of adult rats requires Src activity (Grosshans et al., 2002); (2) internalization of NR2B requires a consensus motif that includes Y1472 (Roche et al., 2001); (3) mutations in

Received Nov. 27, 2008; revised May 12, 2009; accepted May 19, 2009.

This work was supported by the Israel Science Foundation (K.R.). We thank Vicktoria Khatsrinov and Dr. Katya Belelovsky for excellent technical assistance.

Correspondence should be addressed to Dr. Kobi Rosenblum, Department of Neurobiology and Ethology, Faculty of Sciences, University of Haifa, Mount Carmel, Haifa 31905, Israel. E-mail: kobir@psy.haifa.ac.il.

D0I:10.1523/JNEUROSCI.5667-08.2009

Copyright $\odot 2009$ Society for Neuroscience $\quad$ 0270-6474/09/299219-08\$15.00/0
Y1472 NR2B disrupt binding of the clathrin-associated adaptor protein AP-2 to the channel and inhibit NMDAR internalization (Lavezzari et al., 2003; Prybylowski et al., 2005); and (4) in vivo, knock-out of Y1472 results in impaired synaptic plasticity, accompanied by skewed localization of NR1 and NR2B toward the peripheral and perisynaptic regions of the synapse (Nakazawa et al., 2006).

The potential importance of tyrosine phosphorylation of the NMDAR in learning processes was initially proposed in vitro when selective tyrosine kinase inhibitors were shown to block LTP (O’Dell et al., 1991) in a Src/Fyn-dependent manner (Grant et al., 1992; Lu et al., 1998). These findings were later corroborated in vivo in the dentate gyrus of rats (Rosenblum et al., 1996; Rostas et al., 1996). Since then, tyrosine phosphorylated content of NR2B was shown to increase in response to several learning paradigms, including learning of fear (Kojima et al., 2005; Nakazawa et al., 2006) and of taste aversion (Rosenblum et al., 1995; Miyakawa et al., 1997). However, despite the strong correlation between the increase in tyrosine phosphorylation of NR2B and novel taste learning, it has not been determined whether it is necessary for learning a new taste. Here, we hypothesize that introduction of animals to a novel taste results in changes in tyrosine phosphorylation of NR2B, and that prevention of this phosphorylation impairs novel taste memory formation. We further argue that the mechanism underlying taste memory formation involves adequate cellular localization of NMDARs, which also depends on tyrosine phosphorylation of NR2B.

\section{Materials and Methods}

Animal handling

Adult male Wistar Hola or Sprague Dawley rats (Harlan), weighing 200$250 \mathrm{~g}$, were used in all experiments. Standard commercial rat chow and water were available ad libitum, and animals were kept on a $12 \mathrm{~h}$ light/ dark cycle. Animals were handled according to approved protocols and animal welfare regulations of the Institutional Animal Care and Use Committee of the University of Haifa. Protocols were also in accordance with the guidelines laid down by the US National Institutes of Health. 


\section{Behavioral paradigms}

Incidental taste learning. At the beginning of each biochemical or behavioral experiment, animals were separated into individual housing cages and underwent a $3 \mathrm{~d}$ water-restriction training session, in which they received a daily ration of $20 \mathrm{ml}$ of water in two $10 \mathrm{ml}$ pipets, once a day for $20 \mathrm{~min}$. Training ensured that on the day of the experiment the rats drank a sufficient amount of the new taste within the 20 min time frame. On the fourth day, the control group received water, and the experimental group was exposed to an unfamiliar taste $(0.1 \%$ saccharin or $0.3 \% \mathrm{NaCl})$ (Rosenblum et al., 1993).

Conditioned taste aversion. Conditioned taste aversion (CTA) experiments were performed as described previously (Rosenblum et al., 1993). Briefly, the rats underwent a $3 \mathrm{~d}$ training session as described above, and on the fourth day they received either water or an unfamiliar taste, i.e., the conditioned stimulus (CS), comprising $0.1 \%$ saccharin or $0.3 \%$ $\mathrm{NaCl}$. One hour after termination of drinking, both groups were administered the unconditioned stimulus (UCS) in the form of an intraperitoneal injection of the malaise-inducing agent $\mathrm{LiCl}(0.15 \mathrm{M}, 2 \%$ body weight). The rats then received water for two successive days after which a taste-preference test was performed: all the animals were exposed to a multiple choice of either water or the CS for $20 \mathrm{~min}$. Aversion to the novel taste in both the conditioned and the unconditioned animals was measured by calculation of an aversion index, defined as: [(volume of water/ (volume of water + volume of saccharin)] consumed during each test. Accordingly, an aversion index of 0.5 was designated as the chance level, and an increasing index value indicated increasing preference for water over the novel taste.

Latent inhibition. The latent inhibition paradigm was combined with CTA to isolate the effect of taste learning from the potentially confounding effects of the USC and the CS-UCS association. In this procedure, pre-exposure of the animals to a sensory stimulus diminishes its efficacy to serve as an associative stimulus in subsequent learning. Under such conditions, the degree of aversion after CTA training is a measure of memory of the novel taste acquired incidentally in the pre-CTA trial (Rosenblum et al., 1993). Rats in these experiments were pre-exposed to the novel taste $2 \mathrm{~d}$ before the CTA experiment, which significantly reduced their acquired aversion. Testing was performed as described above.

\section{Surgery}

Surgery was performed as previously described (Meiri and Rosenblum, 1998). Male Wistar Hola rats were anesthetized with equithesin $(0.45$ $\mathrm{ml} / 100 \mathrm{~g})\left(2.12 \% \mathrm{w} / \mathrm{v} \mathrm{MgSO}_{4}, 10 \% \mathrm{v} / \mathrm{v}\right.$ ethanol, $39.1 \% \mathrm{v} / \mathrm{v}$ propylene glycol, $0.98 \% \mathrm{w} / \mathrm{v}$ sodium pentobarbital, and $4.2 \% \mathrm{w} / \mathrm{v}$ chloral hydrate), restrained in a stereotactic apparatus (Stoelting), and implanted bilaterally with a stainless-steel guide cannula (23 gauge) in the gustatory cortex (coordinates, with reference to bregma: anteroposterior $=+1.2 \mathrm{~mm}$, lateral $= \pm 5.5 \mathrm{~mm}$, ventral $=5.5 \mathrm{~mm}$ ). The position of the cannula was secured with acrylic dental cement and two skull screws. A stylus was placed in the guide cannula to prevent clogging. After surgery, animals were allowed 1 week of recovery time before the experimental manipulations.

For micro-injection, the stylus was removed from the guide cannula and a 28 -gauge injection cannula was carefully inserted, to extend 0.5 $\mathrm{mm}$ from the tip of the guide cannula. The injection cannula was connected via PE20 tubing to a Hamilton micro-syringe, driven by a CMA/ 100 micro-injection pump (Carnegie Medicin), for an injection rate of 1 $\mu \mathrm{l} / \mathrm{min}$. After injection, the injection cannula was left for an additional $30 \mathrm{~s}$ before withdrawal, to minimize dragging of injected liquid along the injection track.

\section{Sample preparation and immunoprecipitation}

Experiments were terminated by decapitation $60 \mathrm{~min}$ after termination of drinking, and only animals that ingested a sufficient amount of the novel taste $(>10 \mathrm{ml})$ were included in the study (Merhav et al., 2006). After decapitation, the insular cortex was bilaterally dissected and was homogenized in a glass Teflon tissue homogenizer in $1 \mathrm{ml}$ of homogenizing buffer $(50 \mathrm{~mm}$ Tris $\mathrm{pH} 8,150 \mathrm{~mm} \mathrm{NaCl}, 5 \mathrm{~mm}$ EDTA, 1\% v/v $\mathrm{NP}-40,0.5 \%, 0.5 \% \mathrm{w} / \mathrm{v}$ deoxycholic acid, $10 \mathrm{~mm} \mathrm{NaF}, 10 \mathrm{~mm}$ pyrophosphate, $100 \mu \mathrm{m}$ sodium orthovanadate, leupeptin at $10 \mu \mathrm{M} / \mathrm{ml}$, aprotinin at $10 \mu \mathrm{M} / \mathrm{ml}, 0.1 \mathrm{~mm}$ PMSF, $0.1 \% \mathrm{w} / \mathrm{v}$ SDS). Aliquots of $100 \mu \mathrm{l}$ were removed for total fraction assays. Ten minutes after homogenization, samples were centrifuged at $1000 \times g$ and $4^{\circ} \mathrm{C}$ for $2 \mathrm{~min}$, and the supernatants were collected. Protein concentration was determined with the Bradford Assay (Bio-Rad Laboratories), and samples of supernatant, each containing the same amount of protein, were precleared with $2 \mu \mathrm{g}$ of preimmune serum and $20 \mu \mathrm{l}$ of protein $\mathrm{A} / \mathrm{G}$ at $4^{\circ} \mathrm{C}$ for $60 \mathrm{~min}$. The samples were then centrifuged at $20,000 \times g$ for $10 \mathrm{~min}$, and the supernatants were collected and subjected to immunoprecipitation with either mouse anti-phosphotyrosine Sepharose 4B (Zymed Laboratories) or rabbit anti-NR2B (Upstate Cell Signaling Solutions) overnight at $4^{\circ} \mathrm{C}$. On the next day, samples were washed three times with $0.75 \mathrm{ml}$ of homogenizing buffer, diluted in $30 \mu \mathrm{l}$ of $2 \times$ SDS sample buffer, and stored pending analysis.

\section{Synaptoneurosomal fractionation}

Synaptoneurosomal fractions of insular cortex were obtained according to Quinlan et al. (1999). Briefly, the tissues were homogenized in $4 \mathrm{ml}$ of homogenization buffer (10 mм HEPES, 2 mм EDTA, 2 mм EGTA, 0.5 mм DTT, $10 \mathrm{~mm} \mathrm{NaF,} 10 \mathrm{~mm}$ pyrophosphate, $100 \mu \mathrm{m}$ sodium orthovanadate, leupeptin at $10 \mu \mathrm{M} / \mathrm{ml}$, aprotinin at $10 \mu \mathrm{M} / \mathrm{ml}, 0.1 \mathrm{~mm}$ PMSF), and $70 \mu \mathrm{l}$ samples of the homogenized tissue were removed for analysis of total protein fractions. The remaining homogenate was then filtered through a $100 \mu \mathrm{m}$ filter followed by a $5 \mu \mathrm{m}$ filter (Millipore) and centrifuged at $1000 \times g$ for $10 \mathrm{~min}$ at $4^{\circ} \mathrm{C}$. The pellet containing the synaptoneurosomal fraction was resuspended in homogenizing buffer and subjected to SDS-PAGE after protein determination.

\section{Western blot analysis}

All samples were resolved by SDS-PAGE and transferred to nitrocellulose membranes (Bio-Rad Laboratories) for immunoblotting. Blots were visualized by enhanced chemiluminescence with ECL Plus (Amersham Biosciences) and quantified with an XRS charge-coupled device camera (Bio-Rad Laboratories) and Quantity One software. Phosphorylated protein levels were normalized against total levels of unphosphorylated protein.

\section{Reagents}

Rabbit polyclonal anti-phosphotyrosine was obtained from Zymed Laboratories [polyclonal anti-NR2A, polyclonal anti-NR1, and monoclonal PSD 95 (clone K28/43) were purchased from Upstate Biotechnology]. Goat NR2B and $\beta$ actin were obtained from Santa Cruz Biotechnologies. Polyclonal anti-NMDA NR2B (pTyr1472) and protein G plus/protein A-agarose were obtained from Calbiochem. Mouse anti-syntaxin (clone SP8) was obtained from Millipore Bioscience Research Reagents. Mouse anti-synapsin (clone 8) was obtained from Transduction Laboratories (Millipore). All primary antibodies were used at a dilution of 1:1000. Horseradish peroxidase-conjugated donkey anti-goat IgG, goat antirabbit IgG, and goat anti-mouse IgG were obtained from Jackson ImmunoResearch Laboratories and were used at a dilution of 1:10,000. Genistein and ifenprodil were from Sigma. All other reagents were standard laboratory grade.

\section{Statistical analysis}

Data are expressed as means \pm SEM. Statistical significance was determined by means of one-way ANOVA. Post hoc analysis was applied with a Tukey-Kramer multicomparison test when appropriate. A value of $p<$ 0.05 was considered significant.

\section{Results}

To study the role of tyrosine phosphorylation of NR2B in novel taste learning, tyrosine phosphorylated proteins were immunoprecipitated from the insular cortices of rats $1 \mathrm{~h}$ after exposure to either familiar taste water or to the novel taste saccharin. Probing of these samples with a general anti-phosphotyrosine antibody revealed that exposure to saccharin elicits a significant increase in the phosphorylation of a $180 \mathrm{kDa}$ band corresponding to NR2B (Fig. 1A, left). Subsequent probing of the same blots for their NR2B content revealed similar increases in NR2B levels (Fig. $1 A$, 
A IP: $p Y$
IB: $p Y$

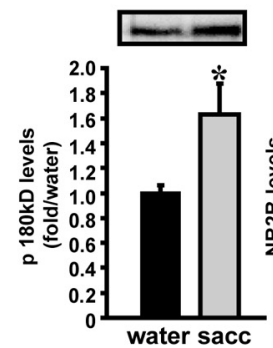

C

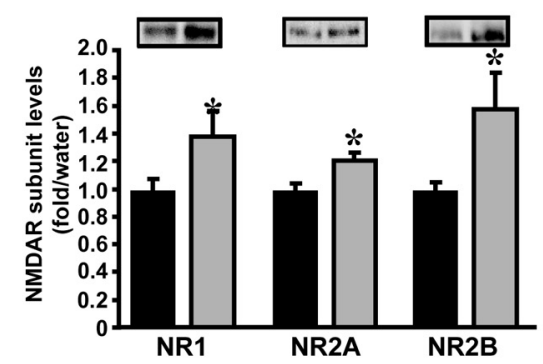

E

\begin{abstract}
IB: p-1472 NR2B
IB: Total NR2B
\end{abstract}

西
B
IP: NR2B
IB: $p Y$

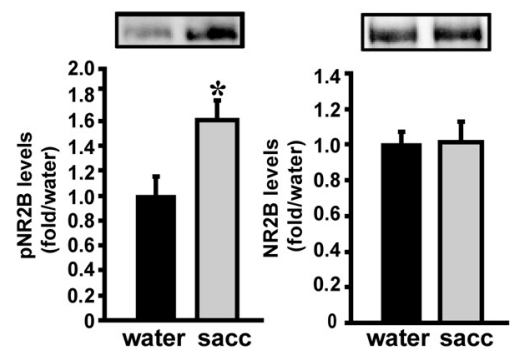

D

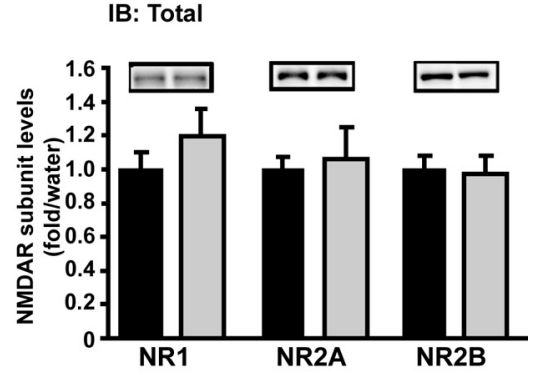

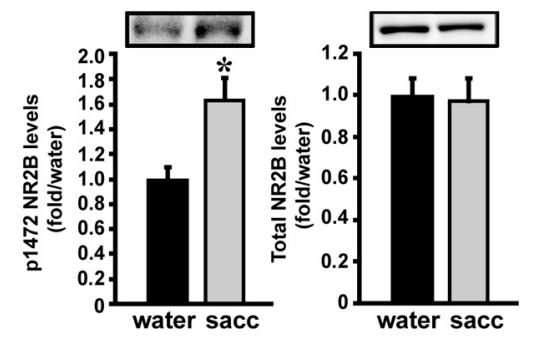

Figure 1. Novel taste learning induces phosphorylation of Y1472 NR2B and increases levels of NMDAR in the phosphotyrosine fractions of the insular cortex. $A$, Immunoprecipitation (IP) of tyrosine-phosphorylated fractions from the insular cortex after novel taste learning. Insular cortices of rats were removed bilaterally $1 \mathrm{~h}$ after ingestion of a familiar taste (water, black bars) or a novel taste [0.1\% saccharin (sacc), gray bars]. Tyrosine-phosphorylated proteins were immunoprecipitated with phosphor-Tyr-specific antibodies (pY) as described in Materials and Methods. The phosphotyrosine content of a band corresponding to $180 \mathrm{kDa}$ was determined from these experiments by immunoblot (IB) (left). The identity of this band was confirmed as NR2B by probing the same immunoprecipitates with anti-NR2B-specific antibody (right). $\boldsymbol{B}$, Immunoprecipitation of total NR2B content from the insular cortex after novel taste learning. Total NR2B protein was immunoprecipitated from brains of water- and saccharinreceiving rats by means of anti-mouse NR2B antibodies, and was probed for phosphotyrosine content with rabbit polyclonal anti-phosphotyrosine (left) and rabbit anti-NR2B (right). C, NR1 and NR2 subunits of NMDA are elevated in the phosphotyrosine fractions of the insular cortex. Immunoprecipitates of tyrosine-phosphorylated proteins from animals treated with water or saccharin were probed with specific anti-NR1, anti-NR2A, or anti-NR2B antibodies. D, No change in total levels of NMDAR after novel taste learning. The different NMDAR subunits in total tissue lysates of insular cortex were probed $1 \mathrm{~h}$ after treatment. $\boldsymbol{E}$, Novel taste exposure elevates tyrosine phosphorylation of the Fyn kinase target Y1472 NR2B. Phospho-Y1472-specific anti-NR2B antibody (left) and total anti-NR2B antibody were used to probe total tissue lysates of insular cortex of rats $1 \mathrm{~h}$ after exposure to water or saccharin. In each panel, a representative immunoblot is shown above a graph depicting mean $\pm \mathrm{SE}$ for three or four independent experiments. *Saccharin versus water, $p<0.05$.

right). To ascertain that these changes were not a result of modifications in protein levels, we performed reciprocal experiments in which total NR2B in the insular cortex was immunoprecipitated and probed for tyrosine phosphorylation. These data show that exposure to novel taste does not change the total NR2B levels in the insular cortex, but instead affects only the levels of phosphorylated NR2B (Fig. 1B).

To test the effect of novel taste learning on the other subunits of the NMDAR, the levels of NR2A and NR1 in the tyrosine phospho complexes of both groups were analyzed. As depicted in Figure $1 C$, all subunits of the NMDAR were found to be elevated in the phospho complex in response to saccharin. Since no changes were observed in the total amounts of the NMDAR $1 \mathrm{~h}$ after exposure to saccharin (Fig. 1D), these increases may either be attributed to increases in the tyrosine phosphorylation contents of NR2A and NR1, in addition to that of NR2B, or simply be attributable to their association with hyperphosphorylated NR2B. Whereas there is no evidence of the occurrence of major tyrosine phosphorylation of NR1 (Lau and Huganir, 1995), NR2A contains several putative tyrosine phosphorylation sites. Probing two of these sites with the phospho-specific antibodies against Y1353 NR2A and Y1387 NR2A has not revealed any significant increase in phosphorylation after novel taste learning (data not shown). Together, these data suggest that that the increased presence of NR2A, as well as that of NR1, was likely attributable to their association with hyperphosphorylated NR2B.

Residue Y1472 was previously identified as the main tyrosine site of NR2B to undergo phosphorylation in vitro (Nakazawa et al., 2001). This Fyn kinase target was shown to play an important role in the formation of LTP and in fear learning (Nakazawa et al., 2001, 2006). To test whether phosphorylation of Y1472 NR2B increases in response to a novel taste, samples from both the familiar and the novel taste groups were probed with a specific antiY1472NR2B antibody. As shown in Figure $1 E$, saccharin caused an increment of $\sim 50 \%$ in phosphorylation of Y1472, which suggests that most of the detected increase in tyrosine phosphorylation of NR2B in response to saccharin exposure likely occurs on this site.

Association of the NMDAR with the postsynaptic density protein PSD-95 through its PDZ domains was shown in many cases to regulate its function (Kornau et al., 1995; Lavezzari et al., 2003). To test the nature of the interaction between NR2B and PSD-95 after novel taste learning, the PSD-95 content was probed in both the total and phosphotyrosine fractions of rats exposed to a familiar or a novel taste. Similarly to the NMDAR findings, whereas the total levels of PSD-95 remained the same in both groups (Fig. $2 \mathrm{~A}$, right), the content of PSD-95 in the phosphotyrosine fractions was significantly elevated (Fig. $2 \mathrm{~A}$, left). To confirm that the observed increase in PSD-95 levels was not attributable to a possible increase in its own tyrosine phosphorylation levels, we immunoprecipitated PSD-95 in both groups and probed the samples for phosphotyrosine and PSD-95 protein levels. A faint band at $95 \mathrm{kDa}$ appeared in both groups after immunoblotting with the general phosphotyrosine antibody. However, no changes were observed in these bands after treatment (Fig. 2B, left). Immunodetection with anti-PSD-95 con- 
A

IP: pY

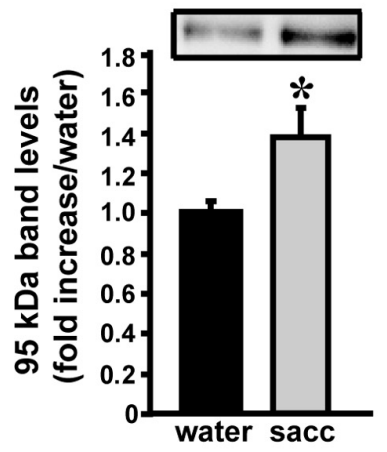

B

$$
\text { IP: PSD } 95
$$

IB: $\mathrm{pY}$

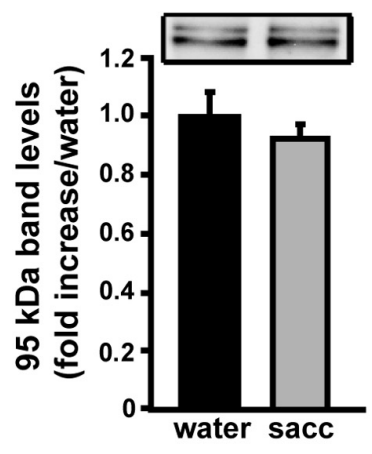

C

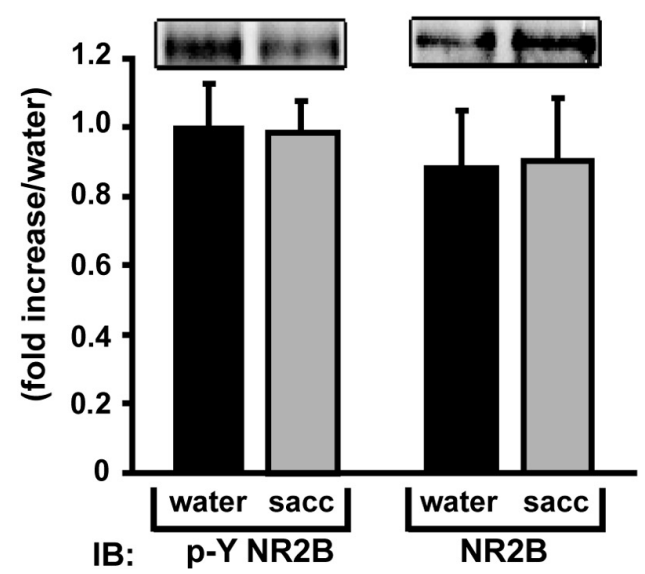

Figure 2. Novel taste learning increases the association of PSD-95 with phosphorylated NR2B.A, Novel taste learning increases the levels of p-NR2B-associated PSD-95. Insular cortices of rats were removed bilaterally $1 \mathrm{~h}$ after ingestion of a familiar taste (water, black bars) or saccharin (sacc; gray bars). The phosphotyrosine content ( $\mathrm{p}-\mathrm{Y}$ ) of a band corresponding to $95 \mathrm{kDa}$ was determined from these experiments (left). The identity of this band was confirmed as PSD-95 by probing the same immunoprecipitates with mouse anti-PSD-95-specific antibody (right). B, No change in total PSD-95 levels after exposure to novel taste. PSD-95 protein was immunoprecipitated from insular cortices of rats $1 \mathrm{~h}$ after ingestion of water or saccharin and probed with a general phosphotyrosine antibody (left) or total PSD-95 (right).C, Total NR2B content and phospho-NR2B levels were probed in the same PSD-95 immunoprecipitates. In each panel a representative immunoblot is shown above a graph depicting mean \pm SE for three or four independent experiments. Other abbreviations are as defined in the legend to Figure 1 . *Saccharin versus water, $p<0.05$.

firmed that $1 \mathrm{~h}$ after novel taste learning there were no changes in total PSD-95 levels (Fig. $2 B$, right). To further ascertain that the increase in PSD-95 content in the phosphotyrosine fraction occurs solely because of its association with hyperphosphorylated
NR2B, PSD-95 immunoprecipitates were probed for the presence phosphorylated and total NR2B. As shown in Figure 2C, no changes were observed in the amount of total or phosphorylated NR2B precipitated with PSD-95, suggesting that exposure to a novel taste causes a significant change only in the fraction of PSD-95 that is associated with hyperphosphorylated NR2B and not in the general NR2B-PSD-95 pool.

The observed increases in phosphorylation and association of NR2B with PSD-95 in response to novel taste exposure were merely correlative, and reflect an observation made at a specific time point after exposure. To find out whether tyrosine phosphorylation of NR2B is in fact necessary for novel taste learning, we inhibited its phosphorylation chemically, and examined the effect this had on the ability of the animals to learn a new taste. Initially, to determine whether phosphorylation of NR2B can be effectively reduced, we applied the general tyrosine kinase inhibitor genistein locally to the insular cortex of naive animals. The phosphotyrosine fractions were isolated by immunoprecipitation and were probed for both phosphorylated and total NR2B. As shown in Figure 3A, bilateral application of genistein to the insular cortex caused an $\sim 60 \%$ reduction in the levels of phosphorylated NR2B. In accordance with this, there was a marked reduction in the amounts of NR2B in the phosphorylated fraction of animals that received genistein.

We then proceeded to determine whether local application of genistein has a behavioral effect on novel taste learning. For this we used the latent inhibition paradigm, whereby CTA in the animals is attenuated by a pre-exposure to the novel taste, in the absence of coupling to a feeling of malaise. Under such conditions, the degree of aversion after CTA training reflects the memory for the novel taste that was acquired incidentally (Rosenblum et al., 1993). In these experiments animals were cannulated bilaterally, and genistein or vehicle was administered $10 \mathrm{~min}$ before the pre-exposure phase. As shown in Figure 3B, animals injected with genistein displayed significantly greater aversion to the novel taste than those in the vehicle-injected group. These levels were similar to those exhibited by animals undergoing CTA without pre-exposure. To show that the effect of genistein was not unique to the saccharin taste, the same type of experiment was repeated with $\mathrm{NaCl}$ used as a different new taste. As in the case of saccharin, animals that received genistein before the preexposure exhibited increased aversion to the $\mathrm{NaCl}$ after training (Fig. 3B, right). Next, to couple the behavioral observations with the biochemical ones, we performed an incidental taste-learning task whereby we exposed four groups of animals to either water or saccharin, having administered injections of genistein or vehicle before their exposure to the novel taste. Samples were collected $1 \mathrm{~h}$ after learning, and the tyrosine content of NR2B was analyzed. As depicted in Figure $3 C$, exposure to saccharin induced a significant increase in NR2B phosphorylation, comparable to those observed previously in the uncannulated animals (see Fig. 1). Application of genistein before saccharin ingestion attenuated this effect, resulting in phosphorylation levels comparable to those displayed by animals receiving the familiar taste. Finally, animals that received a single dose of the NR2B antagonist ifenprodil directly into the insular cortex before CTA training also showed a small but significant decrease in the aversion index (Fig. $3 D$ ). Together, these findings indicate that phosphorylation of the NR2B subunit is not only correlated with, but may in fact be necessary for novel taste learning.

Previous studies have indicated that tyrosine phosphorylation of the NMDAR modulates its cellular distribution, and that these changes in receptor localization may be necessary for synaptic 
A

IP: $p Y$

IB: $\mathrm{pY}$

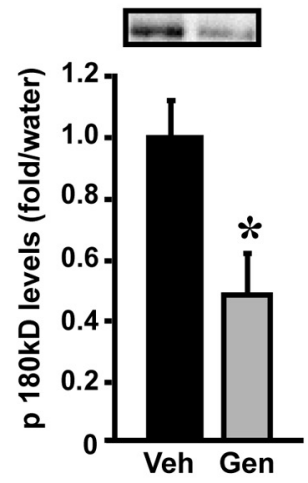

IP: $\mathrm{pY}$

IB: NR2B
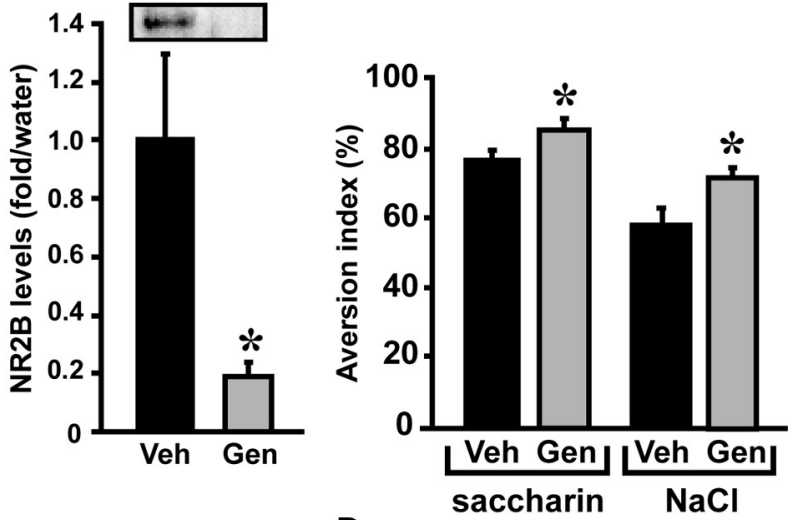

D

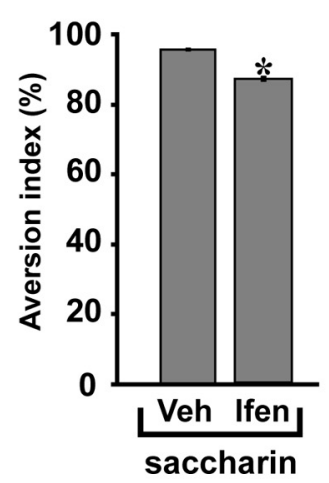

Figure 3. Tyrosine phosphorylation of NR2B is necessary for novel taste learning. $A$, Genistein inhibits phosphorylation of NR2B in the insular cortex. A $1 \mu$ laliquot of $30 \mu \mathrm{mol}$ of genistein (Gen) or vehicle (Veh; $0.3 \%$ DMSO in saline) was injected bilaterally to the insular cortex of naive rats. The rats were killed $1 \mathrm{~h}$ later and tyrosine-phosphorylated proteins were immunoprecipitated with phospho-Tyr-specific antibodies. The tyrosine phosphorylation of the $180 \mathrm{kDa}$ band (left) and total NR2B (right) levels were assayed by using specific antibodies, as described in Materials and Methods. A representative immunoblot is shown above the graph depicting mean \pm SE for two independent experiments. *Saccharin versus water, $p<0.05$. B, Genistein attenuates novel taste learning. Rats received a bilateral injection of $1 \mu \mathrm{l}$ aliquot of $30 \mu \mathrm{mol}$ of genistein or vehicle ( $0.3 \% \mathrm{DMS} 0$ in saline) $10 \mathrm{~min}$ before pre-exposure to the novel taste (saccharin or $\mathrm{NaCl}$ ) or water $(\mathrm{CS}) ; 2 \mathrm{~d}$ later, both groups were exposed to $0.1 \%$ saccharin or $0.3 \% \mathrm{NaCl}$ followed by intraperitoneal injection of $0.15 \mathrm{~m} \mathrm{LiCl}$, as the US. A third group underwent the procedure of CTA without pre-exposure. The animals were tested for their preference for the novel or the familiar taste $2 \mathrm{~d}$ later. Aversion to the novel taste was calculated as described in Materials and Methods. Results are mean $\pm \mathrm{SE}$ for four independent experiments. * ${ }^{\mathrm{G}}$ en or CTA versus Vehicle, $p<0.05$. C, Genistein prevents the increase in NR2B phosphorylation after exposure to a new taste. Bilaterally cannulated animals were injected with either genistein or vehicle $10 \mathrm{~min}$ before a $20 \mathrm{~min}$ single exposure to either saccharin or water. The animals were killed $1 \mathrm{~h}$ after termination of drinking. Tissue was homogenized and immunoprecipitated with antiphosphotyrosine antibody, and the levels of phosphorylated NR2B were assessed as before. $\boldsymbol{D}$, Ifenprodil (Ifen) attenuates novel taste learning. Ifenprodil $(5 \mu \mathrm{M})$ or vehicle was microinjected into the insular cortex 20 min before CTA training (control $n=6$, ifenprodil $n=8$ ). The animals were tested for their preference for the novel or the familiar taste $2 \mathrm{~d}$ later. Aversion to the novel taste was calculated as described in Materials and Methods. Other abbreviations are as defined in the legend to Figure 1. *Ifenprodil CTA versus Vehicle CTA, $p<0.05$.

plasticity and learning (Nakazawa et al., 2006). To further elucidate the role of tyrosine phosphorylation of NR2B in the mechanism of novel taste learning, we studied the levels of phosphorylated and total NR2B in a subcellular fraction of the tissue that is enriched for synaptic proteins (Quinlan et al., 1999). Surprisingly, as opposed to the findings in total tissue homogenate, the levels of Y1472-phosphorylated NR2B were greatly reduced in brains of animals that had consumed saccharin (Fig. 4A, left). Probing for total NR2B levels in these fractions revealed a significant reduction in the actual protein levels (middle), but not in the ratio of phosphorylated to total protein (right), suggesting that the observed decrease in phosphorylation was a direct result of the reduction in the amount of NR2B present in the synaptic area. We next determined the total levels NR1 and NR2A in these fractions, and discovered that $1 \mathrm{~h}$ after saccharin exposure their levels too were significantly decreased (Fig. 4B). To better determine whether these changes could be attributed to a global change in synapse size, the same samples were assayed for two presynaptic proteins, synapsin and syntaxin. As shown in Figure $4 C$, no changes were observed in either protein after novel taste learning, suggesting that the observed changes in NMDA levels were not attributable to an overall change in synapse size. Finally, to establish whether the observed changes in NMDA localization were dependent on tyrosine phosphorylation, levels of NMDA subunits were determined $1 \mathrm{~h}$ after the exposure in the synaptoneurosomal fraction. As shown in Figure $4 D$, genistein did not affect the reduction in NR1 levels, but reversed the relative levels of NR2B and NR2A, yielding synaptic levels similar to those obtained in the animals exposed to the known taste of water.

\section{Discussion}

The major finding of our study is that tyrosine phosphorylation of the NR2B subunit of the NMDAR is a necessary step toward novel taste learning. We showed that $1 \mathrm{~h}$ after a single exposure of rats to saccharin, there is a marked elevation in phosphorylation of Y1472 NR2B and an increased interaction of phosphorylated NR2B with the major postsynaptic scaffold protein PSD-95. Furthermore, injection of a tyrosine kinase inhibitor directly into the insular cortex of rats before exposure to novel taste prevented the increase in NR2B phosphorylation and resulted in a phenotype of animals that were unable to learn the new taste. Last, we found that although a new taste does not change the overall levels of NMDAR, it does cause a significant reduction in its levels in a subcellular area enriched with synaptic proteins. This reduction is prevented after an in vivo injection of the animals with genistein, suggesting a possible role for tyrosine phosphorylation of NR2B in the cellular distribution of the NMDAR after novel taste.

The involvement of tyrosine phosphorylation of the NMDAR in learning processes was indicated by earlier findings that correlated enhanced phosphorylation with various behavioral paradigms. Increased phosphorylation of NR2B was observed in several activities, e.g., hippocampal spatial learning tasks (Mizuno et al., 2003), morphine-seeking behavior in the forebrain (Kato et al., 2006), and in our own study of conditioned taste aversion and novel taste learning in the insular cortex (Rosenblum et al., 1997). The use of transgenic animals overexpressing wild-type or con- 
stitutively active Fyn kinase further supported these findings by showing that enhanced phosphorylation of NR2B is associated with behavior modification such as decreased alcohol withdrawal (Stork et al., 2002), maintenance of neuropathic pain (Abe et al., 2005), and impaired conditioned freezing in fear paradigms (Kojima et al., 2005). However, knock-out of Fyn totally eliminated the phosphorylation of NR2B and prevented neuropathic pain in mice (Abe et al., 2005), and acutely increased their sensitivity to alcohol (Yaka et al., 2003). Furthermore, direct knock-out of Y1472 in mice resulted in impaired fear-related learning and reduced LTP in the amygdala (Nakazawa et al., 2006). Powerful as these studies may be, they are limited as to their ability to evaluate the role of tyrosine phosphorylation of NR2B in the live, adult animals. Here, we show that phosphorylation of NR2B is indeed induced in the insular cortex of an adult animal in the course of novel taste learning, and that attenuation of this process before exposure prevents the formation of that memory. In contrast to other studies in which tyrosine kinase inhibitors were injected either systemically or intraventricularly (Mizuno et al., 2003), we applied the inhibitor locally to the insular cortex, thereby offering a more specific role for cortical NR2B receptor phosphorylation in novel taste learning. The observed increase in tyrosine phosphorylation of NR2B in the insular cortex after introduction of a novel taste was small,

suggesting that novel taste learning induces a change in only a specific fraction of the NMDARs of the insular cortex. This hypothesis is supported by observations in cultured neurons, which showed that among glutamate receptors, NR2 subunits of the NMDARs were the only ones to undergo tyrosine phosphorylation, with an estimated tyrosine phosphorylation of only $3.5 \%$ of NR2B in vivo (Lau and Huganir, 1995).

Both NR2A and NR2B interact directly with PSD-95 at the C terminus of the NMDAR (Kornau et al., 1995), and this interaction may be modulated by either serine or tyrosine phosphorylation. Serine phosphorylation of PSD-95 by CaMKII (calciumcalmodulin-dependent protein kinase II) causes dissociation of NR2A from PSD-95, without interfering with its interaction with NR2B (Gardoni et al., 2006). The role of tyrosine phosphorylation of NR2B in the association with PSD 95 is less clear. Phosphorylation of NR2A and NR2B and their associated proteins by Src or Fyn was found in some cases to enhance their association with PSD-95 (Rong et al., 2001; Zalewska et al., 2005), whereas under conditions of hypoxia that lead to impaired long-term spatial learning and memory there were marked decreases in the levels of PSD-95-NMDAR complex (Chen et al., 2007). One possible role for the formation of this complex is to protect NR2 subunits from undergoing cleavage by calcium-dependent proteases, and thereby to provide a mechanism for regulating NMDAR expression (Dong et al., 2004).

Regulation of NMDAR localization is critical for the forma- tion of memory. Several important studies have closely examined mechanisms of NR2B cellular distribution and found that its surface expression is oppositely regulated through interactions with either PSD-95, which stabilizes receptor expression on the plasma membrane, or with the adaptor protein AP-2, which promotes internalization via the clathrin-coated pit machinery (Roche et al., 2001; Barria and Malinow, 2002; Lavezzari et al., 2003). Another recent study in neuronal primary cultures showed that inhibition of $\mathrm{cdk} 5$, a serine/threonine kinase, results in increased phosphorylation of Y1472 NR2B and decreases activity-dependent endocytosis of NMDARs (Zhang et al., 2008). In this regard, one of the surprising findings of our study was that whereas the total cortex fractions showed a marked elevation in the phosphorylation of NR2B but no changes in the overall levels of NMDAR, the subcellular fraction of synaptoneurosomes showed a marked reduction in the actual levels of NMDA components. These data presumably contradict the previously reported findings; however, the comparison between an in vivo study using a physiological input signal at a very specific time point and studies done in heterologous systems or ex vivo should be carefully considered. The studies showing that mutation in the Y1472 residue of NR2B block NR2B trafficking and increasing the number of synaptic receptors (Lavezzari et al., 2003; Prybylowski et al., 2005) were preformed in heterologous systems or cultured neurons, overexpressing proteins in question. Also, internalization was monitored at much shorter time points (15-30 
min) and not beyond. In our system, the changes in NR2B phosphorylation became detectable only $1 \mathrm{~h}$ of exposure and subsided after $2 \mathrm{~h}$ (data not shown); therefore, we document changes that occur much later than those reported in isolated systems. Therefore, the increased NR2B phosphorylation and association with PSD-95 in total tissue homogenate may reflect a dynamic cellular process intended to normalize a decreased amount of NMDAR in synaptic regions. The fractionation method used to produce synaptoneurosomal fractions in this study merely represents a subcellular fraction that is rich in synaptic proteins and contains both presynaptic and postsynaptic membranes. Therefore, the current findings cannot determine whether the observed reduction in NMDARs in this fraction is attributable to receptor endocytosis or to lateral diffusion away from the synapse, nor can they predict the contribution of PSD-95 to this process. Nonetheless, this process seems to be important for the formation of taste memory because its prevention by genistein is associated with impaired memory to a novel taste.

Another interesting observation in this study concerns the fate of the NMDAR subunits NR2 and NR1. When studying the levels of these components in the synaptoneurosomal fractions, we found that as NR2B, NR2A levels too were reduced. Surprisingly however, pre-exposure to genistein reversed the effect on NR2B and NR2A back to those of the control animals, whereas levels of NR1 continued to be decreased (Fig. 4D). A similar observation was made by Goebel et al. (2005) in adult rat hippocampal slices, where blocking of tyrosine kinase affected the concentration of NR2A and NR2B but not NR1. Furthermore, the subunit composition of NR2 was shown in several instances to direct delivery of receptors to synapses in different ways. Thus, phosphorylation of 1472-NR2B was found to be associated with enrichment of synaptic NMDARs, whereas phosphorylation of 1336-NR2B was associated with enrichment of extrasynaptic NMDARs (GoebelGoody, 2009). Trafficking of NR2 subunits was also found to heavily depend on their specific interaction with scaffolding molecules. Association of NR2B with PSD-95, PSD 93, and SAP97 inhibited its internalization (Roche et al., 2001; Lavezzari, 2003), whereas binding of 1472-NR2B to AP-2 promoted internalization (Lavezzari, 2003). Furthermore, whereas the localization of the NR2B to the synapse was found to be dependent on functional PDZ domains within NR2B, its interactions with the scaffold protein AP-2 cause NR2B to move away from the synapse. In contrast, absence of PDZ domains, or ability to interact with AP-2, had no effect on the synaptic localization of NR2A (Prybylowski et al., 2005). Together, these studies all point to the fact that the NMDAR subunits traffic independently during endocytosis. The effect of these processes on taste learning and memory are yet to be determined.

In summary, we have demonstrated that exposure of rats to a novel taste markedly increases NR2B phosphorylation in the insular cortex, and that this phosphorylation is necessary for the formation of a memory to that taste. Although the mechanisms that underlie this process are only partially understood, we provide evidence that a natural input that is given to a live animal leads to changes in NMDAR phosphorylation and localization. One of the major challenges of this work is to determine in detail the exact patterns and locations of NMDAR movement in response to novel taste exposure, to increase our overall understanding of the connection between learning and memory and biochemical processes that take place in the brain.

\section{References}

Abe T, Matsumura S, Katano T, Mabuchi T, Takagi K, Xu L, Yamamoto A, Hattori K, Yagi T, Watanabe M, Nakazawa T, Yamamoto T, Mishina M, Nakai Y, Ito S (2005) Fyn kinase-mediated phosphorylation of NMDA receptor NR2B subunit at Tyr1472 is essential for maintenance of neuropathic pain. Eur J Neurosci 22:1445-1454.

Barria A, Malinow R (2002) Subunit-specific NMDA receptor trafficking to synapses. Neuron 35:345-353.

Chen Q, He S, Hu XL, Yu J, Zhou Y, Zheng J, Zhang S, Zhang C, Duan WH, Xiong ZQ (2007) Differential roles of NR2A- and NR2B-containing NMDA receptors in activity-dependent brain-derived neurotrophic factor gene regulation and limbic epileptogenesis. J Neurosci 27:542-552.

Cull-Candy S, Brickley S, Farrant M (2001) NMDA receptor subunits: diversity, development and disease. Curr Opin Neurobiol 11:327-335.

Dong YN, Waxman EA, Lynch DR (2004) Interactions of postsynaptic density-95 and the NMDA receptor 2 subunit control calpain-mediated cleavage of the NMDA receptor. J Neurosci 24:11035-11045.

Ehlers MD (2000) Reinsertion or degradation of AMPA receptors determined by activity-dependent endocytic sorting. Neuron 28:511-525.

Gardoni F, Polli F, Cattabeni F, Di Luca M (2006) Calcium-calmodulindependent protein kinase II phosphorylation modulates PSD-95 binding to NMDA receptors. Eur J Neurosci 24:2694-2704.

Goebel SM, Alvestad RM, Coultrap SJ, Browning MD (2005) Tyrosine phosphorylation of the N-methyl-D-aspartate receptor is enhanced in synaptic membrane fractions of the adult rat hippocampus. Brain Res Mol Brain Res 142:65-79.

Goebel-Goody SM, Davies KD, Alvestad Linger RM, Freund RK, Browning MD (2009) Phospho-regulation of synaptic and extrasynaptic $\mathrm{N}$-methyl-d-aspartate receptors in adult hippocampal slices. Neuroscience 158:1446-1459.

Grant SG, O’Dell TJ, Karl KA, Stein PL, Soriano P, Kandel ER (1992) Impaired long-term potentiation, spatial learning, and hippocampal development in fyn mutant mice. Science 258:1903-1910.

Grosshans DR, Clayton DA, Coultrap SJ, Browning MD (2002) LTP leads to rapid surface expression of NMDA but not AMPA receptors in adult rat CA1. Nat Neurosci 5:27-33.

Kato H, Narita M, Miyoshi K, Narita M, Asato M, Hareyama N, Nozaki H, Takagi T, Suzuki M, Suzuki T (2006) Implication of Src family kinasedependent phosphorylation of NR2B subunit-containing NMDA receptor in the rewarding effect of morphine. Nihon Shinkei Seishin Yakurigaku Zasshi 26:119-124.

Kojima N, Sakamoto T, Endo S, Niki H (2005) Impairment of conditioned freezing to tone, but not to context, in Fyn-transgenic mice: relationship to NMDA receptor subunit 2B function. Eur J Neurosci 21:1359-1369.

Kornau HC, Schenker LT, Kennedy MB, Seeburg PH (1995) Domain interaction between NMDA receptor subunits and the postsynaptic density protein PSD-95. Science 269:1737-1740.

Lau LF, Huganir RL (1995) Differential tyrosine phosphorylation of N-methyl-D-aspartate receptor subunits. J Biol Chem 270:20036-20041.

Lavezzari G, McCallum J, Lee R, Roche KW (2003) Differential binding of the AP-2 adaptor complex and PSD-95 to the C-terminus of the NMDA receptor subunit NR2B regulates surface expression. Neuropharmacology 45:729-737.

Lu YM, Roder JC, Davidow J, Salter MW (1998) Src activation in the induction of long-term potentiation in CAl hippocampal neurons. Science 279:1363-1367.

Lüscher C, Xia H, Beattie EC, Carroll RC, von Zastrow M, Malenka RC, Nicoll RA (1999) Role of AMPA receptor cycling in synaptic transmission and plasticity. Neuron 24:649-658.

Meiri N, Rosenblum K (1998) Lateral ventricle injection of the protein synthesis inhibitor anisomycin impairs long-term memory in a spatial memory task. Brain Res 789:48-55.

Merhav M, Kuulmann-Vander S, Elkobi A, Jacobson-Pick S, Karni A, Rosenblum K (2006) Behavioral interference and C/EBPbeta expression in the insular-cortex reveal a prolonged time period for taste memory consolidation. Learn Mem 13:571-574.

Miyakawa T, Yagi T, Kitazawa H, Yasuda M, Kawai N, Tsuboi K, Niki H (1997) Fyn-kinase as a determinant of ethanol sensitivity: relation to NMDA-receptor function. Science 278:698-701.

Mizuno M, Yamada K, He J, Nakajima A, Nabeshima T (2003) Involvement of BDNF receptor TrkB in spatial memory formation. Learn Mem 10:108-115. 
Monyer H, Burnashev N, Laurie DJ, Sakmann B, Seeburg PH (1994) Developmental and regional expression in the rat brain and functional properties of four NMDA receptors. Neuron 12:529-540.

Moon IS, Apperson ML, Kennedy MB (1994) The major tyrosinephosphorylated protein in the postsynaptic density fraction is N-methylD-aspartate receptor subunit 2B. Proc Natl Acad Sci U S A 91:3954-3958.

Nakazawa T, Komai S, Tezuka T, Hisatsune C, Umemori H, Semba K, Mishina M, Manabe T, Yamamoto T (2001) Characterization of Fynmediated tyrosine phosphorylation sites on GluR epsilon 2 (NR2B) subunit of the N-methyl-D-aspartate receptor. J Biol Chem 276:693-699.

Nakazawa T, Komai S, Watabe AM, Kiyama Y, Fukaya M, Arima-Yoshida F, Horai R, Sudo K, Ebine K, Delawary M, Goto J, Umemori H, Tezuka T, Iwakura Y, Watanabe M, Yamamoto T, Manabe T (2006) NR2B tyrosine phosphorylation modulates fear learning as well as amygdaloid synaptic plasticity. EMBO J 25:2867-2877.

O'Dell TJ, Kandel ER, Grant SG (1991) Long-term potentiation in the hippocampus is blocked by tyrosine kinase inhibitors. Nature 353:558 -560.

Prybylowski K, Chang K, Sans N, Kan L, Vicini S, Wenthold RJ (2005) The synaptic localization of NR2B-containing NMDA receptors is controlled by interactions with PDZ proteins and AP-2. Neuron 47:845-857.

Quinlan EM, Olstein DH, Bear MF (1999) Bidirectional, experiencedependent regulation of $\mathrm{N}$-methyl-D-aspartate receptor subunit composition in the rat visual cortex during postnatal development. Proc Natl Acad Sci U S A 96:12876-12880.

Roche KW, Standley S, McCallum J, Dune Ly C, Ehlers MD, Wenthold RJ (2001) Molecular determinants of NMDA receptor internalization. Nat Neurosci 4:794-802.

Rong Y, Lu X, Bernard A, Khrestchatisky M, Baudry M (2001) Tyrosine phosphorylation of ionotropic glutamate receptors by Fyn or Src differentially modulates their susceptibility to calpain and enhances their binding to spectrin and PSD-95. J Neurochem 79:382-390.

Rosenblum K, Meiri N, Dudai Y (1993) Taste memory: the role of protein synthesis in gustatory cortex. Behav Neural Biol 59:49-56.

Rosenblum K, Schul R, Meiri N, Hadari YR, Zick Y, Dudai Y (1995) Modulation of protein tyrosine phosphorylation in rat insular cortex after conditioned taste aversion training. Proc Natl Acad Sci USA 92:1157-1161.
Rosenblum K, Dudai Y, Richter-Levin G (1996) Long-term potentiation increases tyrosine phosphorylation of the $\mathrm{N}$-methyl-D-aspartate receptor subunit $2 \mathrm{~B}$ in rat dentate gyrus in vivo. Proc Natl Acad Sci U S A 93:10457-10460.

Rosenblum K, Berman DE, Hazvi S, Lamprecht R, Dudai Y (1997) NMDA receptor and the tyrosine phosphorylation of its $2 \mathrm{~B}$ subunit in taste learning in the rat insular cortex. J Neurosci 17:5129-5135.

Rostas JA, Brent VA, Voss K, Errington ML, Bliss TV, Gurd JW (1996) Enhanced tyrosine phosphorylation of the $2 \mathrm{~B}$ subunit of the N-methyl-Daspartate receptor in long-term potentiation. Proc Natl Acad Sci U S A 93:10452-10456.

Smart TG (1997) Regulation of excitatory and inhibitory neurotransmittergated ion channels by protein phosphorylation. Curr Opin Neurobiol 7:358-367.

Stork O, Kojima N, Stork S, Kume N, Obata K (2002) Resistance to alcohol withdrawal-induced behaviour in Fyn transgenic mice and its reversal by ifenprodil. Brain Res Mol Brain Res 105:126-135.

Wang YT, Salter MW (1994) Regulation of NMDA receptors by tyrosine kinases and phosphatases. Nature 369:233-235.

Wang YT, Yu XM, Salter MW (1996) Ca(2+)-independent reduction of $\mathrm{N}$-methyl-D-aspartate channel activity by protein tyrosine phosphatase. Proc Natl Acad Sci U S A 93:1721-1725.

Yagi T (1999) Molecular mechanisms of Fyn-tyrosine kinase for regulating mammalian behaviors and ethanol sensitivity. Biochem Pharmacol 57:845-850.

Yaka R, Tang KC, Camarini R, Janak PH, Ron D (2003) Fyn kinase and NR2B-containing NMDA receptors regulate acute ethanol sensitivity but not ethanol intake or conditioned reward. Alcohol Clin Exp Res 27:1736-1742.

Zalewska T, Ziemka-Nałecz M, Domańska-Janik K (2005) Transient forebrain ischemia effects interaction of Src, FAK, and PYK2 with the NR2B subunit of N-methyl-D-aspartate receptor in gerbil hippocampus. Brain Res 1042:214-223.

Zhang S, Edelmann L, Liu J, Crandall JE, Morabito MA (2008) Cdk5 regulates the phosphorylation of tyrosine $1472 \mathrm{NR} 2 \mathrm{~B}$ and the surface expression of NMDA receptors. J Neurosci 28:415-424. 